\title{
Planteamiento por la audiencia nacional de cuestión de inconstitucionalidad contra la imposición de tasas judiciales en la jurisdicción contencioso-administrativa
}

\author{
Mercedes Izquierdo Barragán
}

Letrada de la Junta de Andalucía

SUMARIO. I. GONSIDERACIONES GENERALES. II. LAS DUDAS DE GONSTITUCIONALIDAD PLANTEADAS POR EL AUTO DE LA SALA DE LO CONTENGIOSO-ADMINISTRATIVO DE LA AUDIENGIA NAGIONAL DE 6 DE SEPTIEMBRE DE 2013. III. CONCLUSIONES.

\section{RESUMEN:}

Mediante el Auto de 6 de septiembre de 2013, la Sala de lo Contencioso-administrativo de la Audiencia Nacional, acuerda plantear cuestión de inconstitucionalidad contra varios preceptos de la Ley 10/2012, de 20 de noviembre, por la que se regulan determinadas tasas en el ámbito de la Administración de Justicia y del Instituto Nacional de Toxicología y Ciencias Forenses y del Real Decreto-ley $3 / 2013$, de 22 de febrero, por el que se modifica el régimen de las tasas en el ámbito de la Administración de Justicia y el sistema de asistencia jurídica gratuita.

En concreto, para la Sala de la Audiencia Nacional el artículo 8.2 de la Ley 10/2012, en la redacción dada por el Real Decreto-Ley 3/2013, así como el artículo 1, apartado nueve de este último, posiblemente son contrarios al artículo 24.1 de la Constitución, por cuanto la preclusión del trámite procesal y la terminación del proceso pueden quebrantar el derecho fundamental de la persona a la tutela judicial efectiva, si la exigencia de pago por adelantado de la tasa impide acceder a la jurisdicción contencioso-administrativa, y con ello a obtener dicha tutela judicial efectiva.

De igual manera, los artículos 7.1 y 7.2 de la Ley 10/2012, en la redacción dada por el Real Decreto-Ley 3/2013, pueden ser contrarios a los artículos 14, 9.2 y 31 de la Constitución en la medida en que establecen un régimen económico de las tasas judiciales que no tiene en cuenta el principio de igualdad material, manifestado esencialmente por la capacidad económica del ciudadano. 


\section{ABSTRACT:}

Through Order of September 6, 2013, the National Audience ContentiousAdministrative Section, agrees to raise the issue of unconstitutionality against several provisions of Law 10/2012, of 20 November, regulating certain fees concerning the Administration of Justice and the National Institute of Toxicology and Forensic Sciences and the Royal Decree-Law 3/2013, of February 22, which amends the rates in the field of administration of justice and the legal aid system.

Specifically, to the National Audience Contentious-Administrative Section, Article 8.2 of Law 10/2012, as amended by Royal Decree-Law 3/2013, and Article 1, section nine latter possibly are contrary to Article 24.1 of the Constitution, because the procedural preclusion and the completion of the process may violate the fundamental human right to an effective defence, if the demand for payment of the fee prevents access to the administrative court, and thus to obtain such effective judicial protection.

Similarly, Articles 7.1 and 7.2 of Law 10/2012, as amended by Royal DecreeLaw 3/2013, may be contrary to Articles 14, 9.2 and 31 of the Constitution to the extent that they establish an economic system of court fees that disregards the principle of material equality, primarily manifested by the economic capacity of the citizen.

\section{PALABRAS CLAVES:}

Posible inconstitucionalidad de la obligatoriedad del pago previo de las tasas judiciales por vulnerar el acceso a la jurisdicción, y por ello la tutela judicial efectiva. Posible inaplicación del principio de igualdad material en el régimen económico de las tasas judiciales.

\section{KEYWORDS:}

Possible unconstitutionality of prior obligation to pay legal fees for violating the access to the courts, and therefore effective defence. Possible non-application the principle of material equality in the economic system of court fees. 


\section{GONSIDERACIONES GENERALES}

Resulta evidente el interés que tiene el análisis del Auto de 6 de septiembre de 2013 de la Sala de lo Contencioso-administrativo de la Audiencia Nacional recaído en el recurso contencioso $n^{\circ} 4 / 2013$, por cuanto, aunque con carácter previo se han interpuesto diversos recursos de inconstitucionalidad contra la Ley 10/2012, de 20 de noviembre, por la que se regulan determinadas tasas en el ámbito de la Administración de Justicia y del Instituto Nacional de Toxicología y Ciencias Forenses y el Real Decreto-ley 3/2013, de 22 de febrero, por el que se modifica el régimen de las tasas en el ámbito de la Administración de Justicia y el sistema de asistencia jurídica gratuita, a instancia de cincuenta diputados del Grupo Socialista en el Congreso, la Generalidad de Cataluña y el Consejo de Gobierno de la Junta de Andalucía, y se ha planteado cuestión de inconstitucionalidad de las mismas normas por el Juzgado de lo Social $n^{\circ} 1$ de Tarragona, sin embargo, de un lado, se trata de la primera ocasión en la que se plantea la cuestión de inconstitucionalidad de dichas normas por un órgano jurisdiccional contencioso-administrativo por vulneración del acceso a la dicha jurisdicción, y de otro, el recurso del que deriva tiene por objeto directamente las Órdenes de desarrollo de las citadas normas legales contra las que se plantea la cuestión de inconstitucionalidad.

Efectivamente, el recurso contencioso administrativo se interpuso por una entidad mercantil por el procedimiento especial de protección de los derechos fundamentales de la persona, contra la Orden HAP/490/2013, de 27 de marzo, que modifica la Orden HAP/2662/2012, de 13 de diciembre, por la que se aprueba el modelo 696 de autoliquidación y el modelo 695 de solicitud de devolución del importe de las tasas judiciales, por violación del artículo 24 de la Constitución Española, en el sentido de que, al exigirse el pago de la tasa como requisito inexcusable en los casos que la norma contempla, se estaría infringiendo el derecho fundamental a la tutela judicial efectiva del artículo 24 de la Constitución Española, máxime, si al desatender el requerimiento que a tal efecto haga el Secretario judicial se debe acordar la pérdida del trámite o la terminación del procedimiento no dando lugar a su incoación.

Por tanto, como señala el Auto que ahora se comenta, al plantearse la cuestión de inconstitucionalidad dentro de un recurso contencioso-administrativo, únicamente se plantea dicha cuestión en relación con las tasas exigibles dentro del procedimiento contencioso- administrativo, de conformidad con lo señalado en el artículo 35.2 de la Ley Orgánica del Tribunal Constitucional 2/1979, según el cual es necesario "especificar y justificar en que medida la decisión del proceso depende de la validez de la norma en cuestión". No obstante, a pesar de que el planteamiento de la cuestión de inconstitucionalidad se restringe a las tasas 
exigibles en el procedimiento contencioso-administrativo, la Audiencia Nacional se encarga de señalar que los argumentos sobre los que se sustenta la cuestión de inconstitucionalidad, serían perfectamente de aplicación al orden jurisdiccional civil.

De otra parte, hay que destacar que para plantear la cuestión de inconstitucionalidad no es necesario, como señala el Auto comentado, que, a diferencia del recurso de amparo, la parte actora que ha promovido el procedimiento en el que debe ser de necesaria aplicación la norma cuya constitucionalidad se duda, resulte lesionada en alguno de sus derechos fundamentales, pues el procedimiento para plantear cuestiones de inconstitucionalidad en relación con normas con fuerza de ley subyace en todos los procedimientos jurisdiccionales a través de los cuales se puede llevar a efecto un mecanismo de control abstracto de depuración del ordenamiento jurídico.

Por último, y antes de entrar en el análisis de fondo de la cuestión de inconstitucionalidad planteada, la Audiencia Nacional señala pormenorizadamente la concurrencia de los requisitos constitucional legalmente exigidos para el planteamiento de una cuestión de inconstitucionalidad a efectos de facilitar la admisión de la misma ante el Tribunal Constitucional. En efecto, siendo el planteamiento de la cuestión de inconstitucionalidad una prerrogativa exclusiva e irrevisable del órgano judicial conferida por el artículo 35 de la Ley Orgánica del Tribunal Constitucional como cauce procesal para resolver las dudas que el mismo pueda tener acerca de la constitucionalidad de una ley que se revela de influencia decisiva en el fallo a dictar, es necesario justificar la concurrencia de los requisitos materiales para el planteamiento de la misma, los cuales se desprenden de los artículos 163 de la Constitución y 35.1 Ley Orgánica del Tribunal Constitucional. Así lo hace el Auto de la Audiencia Nacional, indicando que:

A) El primer requisito consistente en que exista una norma jurídica con rango de Ley que pueda entrar en colisión con la Constitución, se cumple en el presente caso, ya que la norma jurídica cuya constitucionalidad se discute es la Ley 10/2012, de 20 de noviembre, según la redacción dada por el Real Decreto-Ley $3 / 2013$, de 22 de febrero, por la que se regulan determinadas tasas en el ámbito de la Administración de Justicia y del Instituto Nacional de Toxicología y Ciencias Forenses.

B) El segundo requisito consistente, es que la norma de cuya constitucionalidad se duda, sea de directa aplicación al caso pendiente de resolución ante los tribunales de justicia, igualmente concurre, puesto que la norma con rango de Ley cuestionada es "aplicable al caso" del que conoce la Audiencia Nacional. Es decir, para la resolución por parte de la Audiencia Nacional del recurso contencio- 
so-administrativo interpuesto contra la Orden HAP/490/2013, de 27 de marzo, que modifica la Orden HAP/2662/2012, de 13 de diciembre, por la que se aprueba el modelo 696 de autoliquidación y el modelo 695 de solicitud de devolución del importe de las tasas judiciales, resulta de aplicación la Ley 10/2012, texto vigente, en cuanto que su artículo 1 prevé que la tasa para el ejercicio de la potestad jurisdiccional en el orden contencioso-administrativo es exigible por igual en todo el territorio nacional, siendo el hecho imponible de la tasa la mera interposición del recurso.

C) En relación con el tercer requisito consistente en que de la validez de la norma cuestionada dependa el fallo, exigiéndose un nexo causal entre la norma y el fallo a pronunciar, de modo que la validez o invalidez de la norma cuestionada originaría una resolución distinta en cada caso, es evidente que concurre. Así, pretendiendo la recurrente la nulidad de las Órdenes HAP/490/2013 y HAP/2662/2012, y constituyendo estas Ordenes el desarrollo reglamentario de la Ley 10/2012, y del Real Decreto-Ley 3/2013, resulta que, si son declarados inconstitucionales alguno de los artículos de estas normas con valor de Ley que desarrollan, las Órdenes que nos ocupan es evidente que la sentencia que deba dictarse en este recurso contencioso- administrativo 4/2013, deberá ajustarse a los pronunciamientos contenidos en la sentencia que resuelva la cuestión de inconstitucionalidad que se plantea.

D) Por último, en cuanto al cuarto requisito relativo a que existan serias dudas de la constitucionalidad de la norma con rango legal, señala la Audiencia Nacional que "el control de legalidad de la actuación administrativa impugnada en el proceso, en cuanto cumple un mandato legal, no puede hacerse sin tener presentes las consecuencias jurídicas que la Ley inexorablemente anuda a la falta de pago de la tasa, de modo que, cuando estos efectos contradicen preceptos constitucionales, ciertamente el precepto legal del que trae causa el desarrollo reglamentario se configura como norma legal de la que depende la validez del fallo". En este sentido, expresamente recoge sus dudas respecto de los artículos 8.2, 7.1 y 7.2, de la Ley 10/2012, según la redacción dada por el Real Decreto-Ley 3/2013, en relación con el artículo 24.1 de la Constitución Española, el primero de ellos, y además con los artículos 14, 9.2 y 31 de la Constitución española, los dos segundos, conforme razona en el cuerpo del Auto y que será objeto de análisis seguidamente. 


\section{LAS DUDAS DE GONSTITUGIONALIDAD PLANTEADAS POR EL AUTO DE LA SALA DE LO CONTENCIOSO-AD- MINISTRATIVO DE LA AUDIENGIA NAGIONAL DE 6 DE SEPTIEMBRE DE 2013.}

Enlazando con el epígrafe anterior, son varias las dudas de constitucionalidad que plantea la Audiencia Nacional en el Auto de 6 de septiembre de 2013. Así, de un lado considera que el artículo 8.2 de la Ley 10/2012, en la redacción otorgada por el Real Decreto-Ley 3/2013 vulnera el artículo 24.1 de la Constitución Española, y de otro que los artículos 7.1 y 7.2 de la misma Norma conculcan lo establecido en 14, 9.2 y 31 de la Constitución española.

\section{Posible inconstitucionalidad del artículo 8.2 de la Ley 10/2012, según la redacción otorgada por el Real Decreto Ley $3 / 2013$.}

Por una parte, el artículo 8.2 de la Ley 10/2012, en la redacción otorgada por el Real Decreto-Ley 3/2013 señala:

"2. El justificante del pago de la tasa con arreglo al modelo oficial, debidamente validado, acompañará a todo escrito procesal mediante el que se realice el hecho imponible de este tributo.

En caso de que no se acompañase dicho justificante, el Secretario judicial requerirá al sujeto pasivo para que lo aporte en el plazo de diez días, no dando curso al escrito hasta que tal omisión fuese subsanada. La ausencia de subsanación de tal deficiencia, tras el requerimiento del Secretario judicial a que se refiere el precepto, dará lugar a la preclusión del acto procesal y a la consiguiente continuación o finalización del procedimiento, según proceda."

Y de otra, el artículo 24.1 de la Constitución española establece:

"1. Todas las personas tienen derecho a obtener la tutela efectiva de los jueces y tribunales en el ejercicio de sus derechos e intereses legítimos, sin que, en ningún caso, pueda producirse indefensión."

El Auto de la Audiencia Nacional parte de que este derecho fundamental de la persona, queda conculcado, no por la exigencia del pago de una tasa, sino por las consecuencias procesales y sustantivas derivadas de la falta de dicho pago.

Así, requerida por el Secretario Judicial la persona que no pague la tasa, y transcurrido el plazo (diez días) concedido para la presentación de la justificación del pago de la tasa o de la concesión de la exención, se produce un efecto, que su petición de acceso a la tutela judicial manifestada en la presentación del escrito de interposición del recurso contencioso administrativo, o de demanda en su ca- 
so, o del correspondiente escrito interponiendo recurso de apelación o casación, quedará precluido procesalmente, y, por tanto, la consecuencia, que conculca el artículo 24.1 de la Constitución, será o la continuación del procedimiento sin haber podido evacuar dicho trámite, o la finalización del procedimiento.

Por tanto, la Audiencia Nacional parte de que la exigencia de una tasa, dentro de ciertos limites y procedimientos y circunstancias, es perfectamente constitucional, pero lo que puede no ser constitucional, es que el pago de dicha tasa, condicione: primero, la posibilidad de acceder a la jurisdicción; y segundo la posibilidad de obtener la tutela judicial; y son estas dos consecuencias inevitables, si no se pagan las tasas, las que se pueden considerar inconstitucionales. En este sentido, se apoya en la Sentencia del Tribunal Constitucional 20/2012, de 12 de febrero, cuando declara que:

«Asimismo, hemos dicho que el derecho a la tutela judicial efectiva no es un derecho de libertad, ejercitable sin más y directamente a partir de la Constitución, sino que es un derecho prestacional y de configuración legal, cuyo ejercicio está sujeto a la concurrencia de los presupuestos y requisitos procesales que, en cada caso, haya establecido el legislador (SSTC 99/1985, de 30 de septiembre, FJ 4 y 182/2004, de 2 de noviembre, FJ 2.)

Ello implica que el legislador cuenta con un ámbito de libertad amplio en la definición o determinación de las condiciones y consecuencias del acceso a la justicia, pues le incumbe configurar la actividad judicial y, más concretamente, el proceso en cuyo seno se ejercita el derecho fundamental ordenado a la satisfacción de pretensiones dirigidas a la defensa de derechos e intereses legítimos (STC 206/1987, de 21 de diciembre, F7 5). En esta regulación, la ley podrá establecer límites al ejercicio del derecho fundamental que serán constitucionalmente válidos si, respetando su contenido esencial (art. 53.1 CE), están dirigidos a preservar otros derechos, bienes o intereses constitucionalmente protegidos y guardan la adecuada proporcionalidad con la naturaleza del proceso y la finalidad perseguida (entre otras, SSTC 158/1987, de 20 de octubre, Ff 4; 32/1991, de 14 de febrero, F7 4; y 133/2004, de 22 de julio, F7 4, recaída precisamente al controlar la constitucionalidad de una norma que limitaba el acceso a la justicia en aras al cumplimiento de deberes tributarios).

En principio, pues, el derecho reconocido en el art. 24.1 CE, puede verse conculcado por aquellas disposiciones legales que impongan requisitos impeditivos u obstaculizadores del acceso a la jurisdicción, si tales trabas resultan innecesarias, excesivas y carecen de razonabilidad o proporcionalidad respecto de los fines que licitamente puede perseguir el legislador ( SSTC 60/1989, de 16 de marzo, Ff 4; 114/1992, de 14 de septiembre, FF 3; y 273/2005, de 27 de octubre, Ff 5).»

En este sentido, considera que las consecuencias de la falta de pago de las tasas judiciales sí pueden constituir trabas que resulten innecesarias, excesivas y ca- 
rezcan de razonabilidad o proporcionalidad respecto de los fines que lícitamente puede perseguir el legislador.

Así, reconociendo la licitud de la finalidad perseguida por el legislador mediante la imposición de las tasas judiciales, cual es subvenir al coste que supone la Administración de Justicia, sin embargo, señala que las consecuencias del incumplimiento de este pago por los que pretenden acceder a la jurisdicción sí pueden tener las características obstaculizadoras indicadas y con ello vulnerar el derecho fundamental de acceso a la jurisdicción.

Con ello, la Audiencia Nacional no hace sino aplicar la misma técnica de proporcionalidad que utiliza el Tribunal Constitucional al resolver en materia de derechos fundamentales, y que se constituye en un canon de enjuiciamiento, no solamente para la aplicación de la norma, sino también para su constitucionalidad en la fase de creación normativa.

El Tribunal Constitucional ha considerado que la proporcionalidad es un principio general del derecho, cuya formulación como concepto jurídico indeterminado, permite un margen de apreciación y en ese sentido se ha abstenido de entrar a conocer de las alegaciones de «desproporción de los medios empleados por el legislador para alcanzar el fin que se le atribuye» cuando responde a un juicio político (STC 66/1985, FJ 1), pero subrayando que sí procede analizar la alegada desproporción cuando «pueda implicar implique un sacrificio excesivo e innecesario de derechos que la Constitución garantiza». La sentencia 96/2012, de 7 de mayo (FJ 10), resalta la relevancia del juicio de proporcionalidad, «una exigencia imprescindible para la constitucionalidad de cualquier medida restrictiva de derechos fundamentales, pues como dijimos, entre otras muchas, en la STC 49/1999, de 5 de abril, FJ 7, el ámbito en el que normalmente y de forma muy particular resulta aplicable el principio de proporcionalidad es el de los derechos fundamentales». En concreto, dicha sentencia 96/2012 (también en el FJ 10) recuerda que ese Tribunal ha declarado en numerosas sentencias que «la desproporción entre el fin perseguido y los medios empleados para conseguirlo puede dar lugar a un enjuiciamiento desde la perspectiva constitucional, cuando esa falta de proporción implica un sacrificio excesivo e innecesario de los derechos que la Constitución garantiza (SSTC 62/1982, de 15 de octubre, FJ 5; 66/1985, de 23 de mayo, FJ 1; 19/1988, de 16 de febrero, FJ 8; 85/1992, de 8 de junio, FJ 5; y 50/1995, de 23 de febrero, FJ 7). Es más, se precisa que «incluso en las Sentencias en las que hemos hecho referencia al principio de proporcionalidad como canon derivado del valor justicia (SSTC 160/1987, de 2 de octubre, FJ 6; 50/1995, FJ 7; y 173/1995, de 21 de noviembre, FJ 2), del principio del Estado de Derecho (STC 160/1987, FJ 6), del principio de interdicción de la arbitrariedad de los poderes públicos (SSTG 6/1988, de 21 de enero, FJ 3; y 
50/1995, FJ 7) o de la dignidad de la persona (STC 160/1987, FJ 6), lo hemos hecho en el contexto de la incidencia de la actuación de los poderes públicos en el ámbito de concretos y determinados derechos constitucionales de los ciudadanos».

En este contexto, la funcionalidad de la proporcionalidad en el derecho es la de establecer una medida, que intenta mantener unos márgenes de actuación, por encima de los cuales una norma o conducta que podría ser acorde con el ordenamiento deja de serlo. Pero se trata de un aspecto cuantitativo, definido como constitucional o no por su grado de intensidad, lo que determina, en el caso que nos ocupa, la necesidad de valorar si, con independencia de la inconstitucionalidad de la existencia de las tasas judiciales, en general, se puede incurrir en inconstitucionalidad, si esa regulación afecta al contenido esencial de los derechos de igualdad y de tutela judicial efectiva. La mejor función de la proporcionalidad se actualiza en aquellas situaciones en las que hay una ponderación muy equilibrada de valores.

Así, la proporcionalidad puede servir para la justificación constitucional a la limitación del derecho. En una relación medio-fin, la proporcionalidad permite un ajuste entre derechos, una limitación en el uso de un derecho en relación con otro, pero esta limitación recíproca de derechos sólo se podrá dar en niveles homologables de derechos y bienes constitucionales. En el juicio de necesidad ya sí habría elementos valorativos, y la exigencia de que no haya sido posible otra medida igualmente eficaz pero no restrictiva del derecho (STC 66/1995).

En suma, la proporcionalidad y la ponderación de los intereses en conflicto exigen un pronunciamiento sobre la intensidad con que pueden defenderse uno y otro derecho, y hasta qué punto es exigible el sacrificio de la alternativa menos favorable (STC 120/1990; en ese caso pondera la colisión entre el art. 15 y el art. $16 \mathrm{CE})$.

De este modo, si no se tiene en cuenta la proporcionalidad que debe regir entre el fin perseguido por la norma cuestionada, cual es la de financiar el servicio público de la Administración de Justicia con cargo a los justiciables que más se benefician de la actividad jurisdiccional, disminuyendo correlativamente la financiación procedente de los impuestos, a cargo de todos los ciudadanos; y los principios de capacidad económica, igualdad, equidad y justicia que debe presidir todo sistema tributario que pretende garantizar el sostenimiento de los gastos públicos a que se refiere el art. 31 de la Constitución Española, como incluso lo reconoce el apartado II de la Exposición de Motivos de la Ley 10/2012 al afirmar de manera explícita que "asimismo, la determinación de la carga tributaria no se hace a partir de la capacidad económica del contribuyente, sino del coste 
del servicio prestado, que nunca puede superarse", se conculca el citado derecho fundamental.

Precisamente, es la STC de 16 de febrero de 2012, la que lleva a esta Sala a fundar su sospecha sobre la constitucionalidad de los preceptos que se cuestionan, ya que en sus Fundamentos Jurídicos 9 y 10 concluye que "en todo caso, desde nuestra perspectiva, debemos poner de manifiesto que en principio no vulnera la Constitución que una norma de rango legal someta a entidades mercantiles, con un elevado volumen de facturación, al pago de unas tasas que sirven para financiar los costes generados por la actividad jurisdiccional que conlleva juzgar las demandas que libremente deciden presentar ante los Tribunales del orden civil para defender sus derechos e intereses legitimos.

Esta conclusión general sólo podría verse modificada si se mostrase que la cuantía de las tasas establecidas por la Ley 53/2002, de 30 de diciembre, son tan elevadas que impiden en la práctica el acceso a la jurisdicción o lo obstaculizan en un caso concreto en términos irrazonables, atendiendo a los criterios de la jurisprudencia expuestos en el fundamento jurídico 7".

Igualmente, señala que la limitación de acceso al recurso puede ocurrir teniendo en cuenta la reducida capacidad económica de muchas personas, mas aún cuando se tiene en cuenta las cargas familiares a las que deben hacer frente, circunstancias todas ellas que lejos de contribuir al sostenimiento de los gastos de la administración de justicia persiguen un efecto contrario, cual es el de reducir de manera drástica la litigiosidad al que debe hacer frente el sistema judicial español y que solo permitiría el acceso a la justicia de aquellas personas físicas con suficientes recursos económicos, así como también a las personas jurídicas de las que se debe presumir sobre prueba en contrario que cuentan con liquidez bastante para litigar, lo que supondría una manifiesta desigualdad en el acceso a la jurisdicción.

En este sentido recuerda, la doctrina del Tribunal Europeo de Derechos Humanos en relación al art. 6.1 del Convenio de Roma de 4 de noviembre de 1950 de Protección de Derechos Humanos y de las Libertades Fundamentales, ratificado por España el día 24 de noviembre de 1977 (BOE 10 de octubre de 1979), resumiéndola en la Sentencia de la Sección $3^{\mathrm{a}}$, de 7 de febrero de 2008, recurso $n^{\circ} 4113 / 2003$, según la cual si bien, el derecho a un tribunal no es absoluto, sino que se presta a limitaciones, pues requiere por su propia naturaleza una reglamentación estatal que tiene la elección de los medios a emplear para este fin, sin embargo, a este respecto, el Tribunal recuerda que no ha excluido nunca que los intereses de una buena administración de justicia puedan justificar la imposición de una restricción financiera al acceso de cualquier persona a un tribunal. 
El Tribunal subraya que una limitación del acceso a un tribunal no se concilia con el artículo 6.1 salvo si persigue una finalidad legítima y si existe una relación razonable de proporcionalidad entre los medios empleados y la finalidad perseguida.

En lo relativo en particular a la exigencia del pago a las jurisdicciones civiles (lo cual nada impide extrapolarlo al orden social o contencioso-administrativo) de una tasa judicial relativa a las demandas de que deben conocer, no pueden considerarse como una restricción al derecho de acceso a un tribunal que fuera en sí misma incompatible con el artículo 6.1 del Convenio. Sin embargo, el Tribunal reitera que el importe de los gastos apreciado a la luz de las circunstancias de un asunto determinado, incluida la situación financiera del recurrente y la fase del procedimiento en la que la restricción en cuestión se impone, son factores a tomar en cuenta para determinar si el interesado se ha beneficiado de su derecho de acceso a un tribunal, o si, por razón del importe de los gastos exigidos, éste ha sido restringido hasta un punto tal que el derecho se encuentra afectado en su propia sustancia.

De lo expuesto llega a la conclusión de que el hecho de que para recurrir no se tenga en cuenta la situación financiera del actor -al margen de los beneficios de justicia gratuita- supone que en no pocas ocasiones, lleva a restringir el acceso a la jurisdicción y por ende al recurso correspondiente, incumpliendo el Estado español, al igual que concluye el Tribunal Europeo de derechos Humanos en la citada sentencia de 2008 con su obligación de regular el acceso a un tribunal de manera conforme a las exigencias del art. 6.1 del convenio, así como del art. 24.1 CE en cuya contradicción existen serias sospechas de que incurren los preceptos cuestionados por la Audiencia Nacional.

Concluye pues, que el hecho de exigir al recurrente el pago de una tasa, que en algunos casos resulta desproporcionada, coartaría su derecho a la tutela judicial efectiva en su vertiente de acceso a la jurisdicción y en su caso al recurso, porque se vería impedido para su correspondiente presentación al carecer de suficientes recursos económicos a tal efecto.

Dicha afirmación, finalmente, es sustentada por el Auto en un principio de certeza o de prueba de la realidad social y jurisdiccional, a través de los datos aportados por el propio Consejo General del Poder Judicial en su informe de 11 de junio de 2013, que demuestran que las tasas exigidas con carácter simultaneo a la presentación del escrito de interposición del recurso contencioso-administrativo con la "sanción" que conlleva el no hacerlo, suponen un obstáculo que impide el acceso a la jurisdicción y, por ello, a la tutela judicial efectiva. Y ello porque conforme al citado informe, se llega a la conclusión que desde la entrada en 
vigor de las Ordenes HAP/2662/2012 y HAP/490/2013, se ha reducido de manera considerable, llamativa y preocupante el número de recursos interpuestos por los ciudadanos, pudiéndose deducir que la implantación del pago previo de las tasas y de las consecuencias de su falta de pago, han impedido e impiden que aquellas personas que necesiten acceder a los tribunales de justicia, no puedan hacerlo, o decidan soportar las consecuencias de actos y actuaciones de la Administración sin el refrendo del sistema natural del control jurisdiccional, establecido en la Constitución, artículo 106.

Así, en dicho informe literalmente se refleja que:

"Por jurisdicciones, se observa un apreciable efecto de las tasas judiciales en la reducción del número de procedimientos interpuestos por los ciudadanos contra la Administración pública en la vía contenciosa-administrativa. Así, el número de asuntos en esta jurisdicción descendió un $14,9 \%$, sin tener en cuenta las demandas masivas por las bajadas de salarios a los trabajadores públicos ya que fueron eliminadas del análisis.

En cifras, en los juzgados de lo contencioso se esperaba el ingreso de más de 56.000 asuntos en este tiempo, cuando al final este número se sitúa en 48.164 asuntos.

Respecto a la actividad administrativa sancionadora, cuya competencia es de la Audiencia Nacional, el descenso ha sido del 36,3\%.

En los tribunales superiores de justicia, sin tener en cuenta los casos de función pública, los asuntos ingresados han sido 14.738 frente a los más de 18.000 esperados, por lo que la rebaja ha sido del 19,1\%."

\section{Posible inconstitucionalidad del artículo 7.1 y 2 de la Ley 10/2012, según la redacción otorgada por el Real Decreto Ley $3 / 2013$.}

Conforme a lo expuesto, el Auto de la Audiencia Nacional señala que teniendo en cuenta la Sentencia del Tribunal Constitucional 20/2012, si bien el modelo del servicio público de la prestación de la justicia, es competencia del legislador en nuestro sistema democrático constitucional, pudiendo elegir entre un sistema de total gratuidad, con cargo a los impuestos generales, o el establecimiento de un sistema mixto de forma que se sufrague en parte por quien, haga uso de dicho servicio, salvo que se encuentre en alguno de los supuestos legales en que así se le reconozca; no obstante, si el legislador elige un sistema mixto de forma que se sufrague por quien haga uso de dicho servicio, debe tener en cuenta otro derecho fundamental recogido en el artículo 14 de la Constitución Española: "Los españoles son iguales ante la Ley, sin que pueda prevalecer discriminación alguna 
por nacimiento, raza, sexo, religión, opinión o cualquier otra condición o circunstancia personal o social," en relación con el artículo 9.2 de la misma Constitución: "Corresponde a los poderes públicos promover las condiciones para que la libertad y la igualdad del individuo y de los grupos en que se integra sean reales y efectivas: remover los obstáculos que impidan dificulten su plenitud y facilitar la participación de todos los ciudadanos en la vida politica, económica, cultural y social;" y con el artículo 31.1 de la Constitución Española de 1978 que establece que: "todos contribuirán al sostenimiento de los gastos públicos de acuerdo con su capacidad económica mediante un sistema tributario justo inspirado en los principios de igualdad y progresividad que, en ningún caso, tendrá alcance confiscatorio."

De esta forma se plantea también la posible inconstitucionalidad del artículo 7.1 y 2 de la Ley 10/2012, en la redacción dada por el Real Decreto Ley 3/2013, por posible infracción del artículo 14 en relación con el 9.2, y 31.1 de la Constitución Española, en la medida en que fija el importe de las tasas en el orden jurisdiccional contencioso administrativo tanto en su cantidad fija, como variable.

Y ello porque la Constitución española se esfuerza por lograr la igualdad material, trata de conseguir un trato desigual a quien se encuentra en situaciones desiguales, para que de esta forma se alcance la igualdad material, haciendo hincapié en la necesidad de que el legislador no trate a todos los individuos de la misma manera sino que sea capaz de tratar de forma diferente aquellas situaciones que son distintas en la vida real. Así, ha afirmado en varias sentencias que "lo proclamado en el artículo 9.2 puede exigir un mínimo de desigualdad formal para progresar hacia la consecución de la igualdad sustancial".

En este sentido, el artículo 14 de la Constitución, declara el derecho fundamental de la persona a la igualdad formal en la Ley y ante su aplicación, el artículo 9.2 exige se implante el derecho a la igualdad material. La diferencia o complemento entre la igualdad formal y la material es recogido en la sentencia del Tribunal Constitucional 34/1981, de 10 de noviembre, según la cual:

"El principio de igualdad jurídica consagrado en el art. 14 hace referencia inicialmente a la universalidad de la ley, pero no prohíbe que el legislador contemple la necesidad o conveniencia de diferenciar situaciones distintas y de darles un tratamiento diverso, que puede incluso venir exigido, en un Estado social y democrático de Derecho, para la efectividad de los valores que la Constitución consagra con el carácter de superiores del Ordenamiento, como son la justicia y la igualdad (art. 1), a cuyo efecto atribuye además a los poderes públicos el que promuevan las condiciones para que la igualdad sea real y efectiva ( art. 9.2)."

Sobre el significado general y el alcance de esta igualdad material se pronuncia la Sentencia del Tribunal Constitucional 83/1984, de 24 de julio, señalando que: "No implica sin embargo este precepto (el art. $14 \mathrm{CE}$ ), en modo alguno, la necesidad de 
que todos los españoles se encuentren siempre, en todo momento y ante cualquier circunstancia, en condiciones de absoluta igualdad, pues esta igualdad real, cuya procura encomienda la Constitución (art. 9.2) a todos los poderes públicos y que es una Finalidad propia del Estado social y democrático de Derecho, no impide que, en la práctica, el ejercicio de determinadas actividades requiera la posesión de determinados medios." No obstante en algunas ocasiones el alto Tribunal afirma que el principio de igualdad material contenido en el artículo 9.2 constituye a los poderes públicos en la obligación de hacerlo realidad, como la Sentencia 27/1981, de 20 de julio, según la cual:

"El acto del Legislativo se revela arbitrario (...) cuando engendra desigualdad. $\Upsilon$ no ya desigualdad referida a la discriminación - que ésta concierne al art. 14, sino a las exigencias que el 9.2 conlleva, a fin de promover la igualdad del individuo y de los grupos en que se integra, finalidad que, en ocasiones, exige una política legislativa que no puede reducirse a la pura igualdad ante la ley."

Por otro lado, y como consecuencia de lo anterior, se encarga de recordar el Auto que, en el ámbito del orden jurisdiccional contencioso-administrativo, no debe olvidarse que la otra parte, contraria al administrado, es la Administración, que goza de unas potestades y prerrogativas exorbitantes, cuyo control lo tienen, en última instancia, los tribunales de justicia, quienes con arreglo a la Constitución (artículo 117), y dentro de un Estado de Derecho, son los órganos encargados de interpretar y aplicar el derecho al caso concreto, si bien como se demuestra del informe del Consejo General del Poder Judicial aludido anteriormente, por los datos estadísticos reverenciados, se ha limitado efectivamente el acceso a la jurisdicción y con ello a la posibilidad del ejercicio del derecho fundamental de la tutela judicial efectiva, y de la prestación, por parte del Estado, de este servicio mínimo e ineludible (artículo 149.1.5 de la Constitución).

Todo ello sin que la ruptura de dicho principio de igualdad material quede paliada por Ley 1/1996, de Asistencia Jurídica Gratuita y los supuestos de exención objetiva y subjetiva recogidos en la propia Ley 10/2012 y Real Decreto-Ley $3 / 2013$.

Así, de la regulación de cuya constitucionalidad se duda se deduce que, en el orden contencioso administrativo, solamente existe una exención objetiva en el artículo 4.1.f): "La interposición de recursos contencioso-administrativos cuando se recurra en casos de silencio administrativo negativo o inactividad de la Administración."Y en las excepciones subjetivas solamente a los funcionarios públicos cuando actúen en defensa de sus derechos estatutarios, y lógicamente a quien haya obtenido el beneficio de asistencia jurídica gratuita. Las demás exenciones se refieren al Ministerio Fiscal, a los Altos Organismos de la Nación y a la Administración. 
La obtención del beneficio de asistencia jurídica gratuita, únicamente beneficiará a un sector de la población, que después de seguir un procedimiento especifico, acredite que sus recursos o ingresos no excedan del quíntuplo del indicador público de renta de efectos múltiples, teniendo en cuenta además la carencia de patrimonio suficiente; en todo caso este reconocimiento será de naturaleza excepcional.

Pero no se ha pensado en la gran mayoría de la población, que no hallándose en alguna de las situaciones legales para obtener la asistencia jurídica gratuita, sin embargo tenga unos ingresos que superen lo mínimos legales, pero con unos gastos corrientes que absorban sus ingresos, y que deberá hacer un desembolso personal para el pago previo de las tasas, no deducible en otros impuestos específicos, como sucede a las personas jurídicas.

De esta forma, será el administrado, en todo caso, el que debe, o soportar el contenido del acto administrativo, o sufrir la carga de tener que pagar de forma anticipada el importe de unas tasas, que por si solas pueden suponer un gravamen igual o mayor que el propio contenido de aquel. Esto puede constituir un impedimento innecesario y no justificado para poder acceder a obtener la tutela judicial efectiva.

Por otro lado, el Auto llega a la conclusión de que, atendiendo a la cuantía de las tasas, al pago previo de las mismas, y a la imposibilidad de continuar el procedimiento en caso de no pago, se puede poner en manos de la Administración, una potestad de disposición indirecta del ejercicio del derecho fundamental de la tutela judicial efectiva. La Administración de antemano, en base a los datos estadísticos de los que dispone, puede conocer los limites que el administrado es capaz de soportar sin impugnar el acto administrativo del que es destinatario, de forma que, fije su contenido, de manera que el ciudadano decida acatar el contenido del acto, en lugar de impugnarlo, al serle menos gravosa aquella solución que ésta. Con ello la finalidad disuasoria de las tasas resulta patente en numerosos supuestos en que la impugnación de actos administrativos de escasa cuantía o trascendencia económica que van a quedar al margen del control jurisdiccional.

En este sentido, analizado el importe de las tasas en los distintos procedimientos (artículo 7.1 de la Ley 10/2012) la Audiencia Nacional deduce que los interesados prescindirán de ejercer su derecho a la tutela judicial, cuando, al margen de otras consideraciones, el importe de la tasa sea superior al del acto cuestionado; y sin que la corrección introducida en el artículo 7.1 por el Real Decreto- Ley 3/2013 para las resoluciones sancionadoras, cuya cuantía no podrá exceder del 50 por ciento del importe de la sanción económica impuesta, sea sufi- 
ciente para garantizar el ejercicio del derecho pues es conocida la reducción -precisamente al 50 por ciento- de las sanciones en innumerables supuestos cuando se opta por no impugnarlas.

Por último, la Audiencia Nacional reconoce que aun cuando en el Auto por el que se trasladó a las partes para alegaciones el posible planteamiento de la cuestión de inconstitucionalidad, se omitió una posible conculcación del artículo 106 de la Constitución española, sin embargo en el Auto que estamos comentando, señala que la privación del acceso a la jurisdicción trae consigo una consecuencia de indudable trascendencia constitucional como es la ausencia de control de la jurisdicción contencioso-administrativa sobre la legalidad de la actuación administrativa, tal y como se encargó de poner de relieve la Sentencia 20/2012 del Tribunal Constitucional al señalar que "En este proceso constitucional tampoco procede analizar las tasas que gravan el ejercicio de la jurisdicción contencioso- administrativa, cuyo acceso también ofrece peculiaridades desde el punto de vista constitucional, consecuencia del mandato contenido en el art. 106.1 CE que ordena y garantiza el control jurisdiccional de la Administración por parte de los Tribunales ( SSTC 294/1994, de 7 de noviembre, FF 3, y 177/2011, de 8 de noviembre, F7 3; en el mismo sentido, STEDH Gran Sala Perdigáo c. Portugal, de 16 de noviembre de 2010, as. 24768/06, § 72)".

Así, en el orden contencioso-administrativo se defienden los intereses particulares de quienes se sienten perjudicados por un acto administrativo ilegal, pero al accionar frente a la Administración en tales supuestos se fortalece un interés colectivo en la lucha por el afianzamiento del Estado de Derecho. Si el acceso a la Justicia en general implica, ya de por sí, beneficios colectivos que trascienden el interés del justiciable considerado individualmente (STC 20/2012), piénsese hasta dónde alcanza esta conclusión cuando se impugnan actos de la Administración por particulares interesados en la preservación de bienes colectivos como el urbanismo, el medio ambiente, etc. Por ello, la imposición indiscriminada de una tasa en el orden contencioso-administrativo, hace muy difícil que se acuda al control de la actuación administrativa por los Tribunales de justicia con la evidente vulneración del artículo 24 en relación con el 106 de la Constitución.

\section{GONGLUSIONES}

En definitiva, el Auto de 6 de septiembre de 2013 llega a las siguientes conclusiones que le llevan al planteamiento de la cuestión de inconstitucionalidad:

- El artículo 8.2 de la Ley 10/2012, en la redacción dada por el Real Decreto-Ley $3 / 2013$, así como el artículo 1, apartado nueve de este último, posiblemente son contrarios al artículo 24.1 de la Constitución, por cuanto la preclusión 
del trámite procesal y la terminación del proceso pueden quebrantar el derecho fundamental de la persona a la tutela judicial efectiva, si la exigencia de pago por adelantado de la tasa impide acceder a la jurisdicción contencioso-administrativa, y con ello a obtener dicha tutela judicial efectiva.

- Los artículos 7.1 y 7.2 de la Ley 10/2012, en la redacción dada por el Real Decreto-Ley 3/2013, pueden ser contrarios a los artículos 14, 9.2 y 31 de la Constitución en la medida en que establecen un régimen económico de las tasas judiciales que no tiene en cuenta el principio de igualdad material, manifestado esencialmente por la capacidad económica del ciudadano, y, sin que se considere que los supuestos de exención objetiva y subjetiva recogidos en la citada Ley, así como la regulación de la obtención de la Asistencia Jurídica Gratuita, sean criterios correctivos suficientes, para lograr la igualdad material pretendida constitucionalmente.

- El artículo 12 de la Orden HAP/2662/2012 y la redacción que da a dicho artículo por la Orden HAP/490/2013, que aprueban los modelos 695 y 696 para el pago de las tasas, objeto del recurso contenciosos-administrativo, no serian de aplicación si los artículos de la Ley que reglamentariamente desarrollan (7.1.y 2 y 8.2) son declarados inconstitucionales. 